\title{
Vaginal Obstruction
}

National Cancer Institute

\section{Source}

National Cancer Institute. Vaginal Obstruction. NCI Thesaurus. Code C78700.

Congenital or acquired blockage of the vagina. 